\title{
Koulutusorganisaatiot yhteiskunnan uudistajina
}

\author{
Erkka Laininen ja Arto O. Salonen
}

\section{TIIVISTELMÄ}

Kestävän tulevaisuuden välttämätön edellytys on, että omaksumme edistyskäsityksen, jossa hyvää elämää tavoitellaan yhden planeetan rajoissa. Tässä artikkelissa etsimme ratkaisua rakenteelliseen dilemmaan, jossa koulutuksen tehtäväksi asetetaan samanaikaisesti olemassa olevaa kulttuuria toisintava sosialisaatio ja kokonaisvaltaisen yhteiskunnallisen muutoksen aikaansaaminen. Tunnistamme keinoja, joiden avulla koulutusorganisaatiot voivat omaksua tarkoituksekseen yhteiskunnan uudistamisen ja kestävän tulevaisuuden rakentamisen. Varhaiskasvatussuunnitelman perusteisiin sekä perusopetuksen ja lukioiden opetussuunnitelmien perusteisiin tullut ekososiaalinen sivistyskäsitys luo uudistavalle oppimiselle kasvatusfilosofisen perustan. Oppimisen tasojen teoriasta (Bateson 1972; Sterling 2003) on johdettavissa viitekehys, jonka avulla on mahdollista tarkastella koulutusorganisaation paradigman muutosta olemassa olevaa toisintavasta orientaatiosta kohti tulevaisuutta ennakoivaa ja yhteiskuntaa uudistavaa orientaatiota. Tunnistamme orientaatioiden toteutumisen tunnusmerkeiksi ja paradigman muutosta vahvistaviksi tekijöiksi koulutusorganisaation suhteen yhteiskuntaan, organisaatiosta nousevan eli emergentin uudistumisen sekä organisaation tulevaisuusorientaation ja oppimiskäsityksen. Viitekehyksemme havainnollistaa kuinka transformatiivisuus laajenee yksilön oppimisesta yhteisölliseksi sosiaalipedagogiikaksi, joka kumuloituu uudistavien kumppanuuksien kautta yhteiskunnalliseksi muutokseksi.

Avainsanat: koulutusorganisaatio, ekososiaalinen sivistys, transformatiivinen oppiminen, kestävä tulevaisuus 


\section{ABSTRACT \\ EDUCATION ORGANISATIONS AND SOCIETAL TRANSFORMATION TOWARDS A SUSTAINABLE FUTURE}

A necessary precondition for a sustainable future is adopting an ideal of progress in which the aspiration to a good life is obtainable within the limits of one planet. In this article we search for a solution to a structural dilemma in which socialisation and reproduction of our prevailing culture and a comprehensive transformation of society manifest simultaneously as targets for education. We identify the means through which educational organisations can adopt a mission of societal transformation and construct a sustainable future. From the perspective of philosophy of education, the concept of eco-social education, introduced in the Finnish core curricula for early childhood and care, basic education, and general upper secondary education, provides a basis for transformative learning. Based on the theory of levels of learning (Bateson 1972; Sterling 2003), a framework can be derived making it possible to examine the paradigm shift of educational organisation from a reproductive orientation towards forecasting and transformative orientations. We identify an organisation's relationship with its operational environment, emergence, future orientation and conception of learning as characteristics for these orientations and as central factors of change. Our model describes how transformative learning extends from individual learning into collective social pedagogy, which further accumulates as societal change through transformative partnerships.

Key words: educational organisation, eco-social education, transformative learning, sustainable future

\section{Johdanto}

hmisten elämä ja yhteiskuntien toiminta ovat materiaalisesti suljetun systeemin muodostavalla maapallolla täysin riippuvaisia biosfäärin elinvoimaisuudesta. Kestävä tulevaisuus edellyttää ilmastonmuutoksen, luonnon monimuotoisuuden köyhtymisen ja luonnonvarojen ehtymisen hidastamista ja pysäyttämistä. (Folke, Biggs, Norström, Reyers \& Rockström 2016; Steffen ym. 2015.) Kiertotalous, päästötön energia ja digitalisaatio ovat keinoja vallitsevan kehityskulun hidastamiseen. Kehityksen pysäyttämiseen ne eivät kuitenkaan näytä riittävän, ellemme samanaikaisesti kyseenalaista vallalla olevan edistysajattelun perustana olevia käsityksiämme ihmisestä, ympäröivästä maailmasta sekä ihmisen ja muun luonnon välisestä suhteesta. (Järvensivu 2019; BIOS-tutkimusyksikkö 2018; Vaden ym. 2019; Värri 2018; Sterling 2003; 2019.) 
Koulujärjestelmiä on niin Suomessa kuin maailmallakin valjastettu varmistamaan olemassa olevan yhteiskunnan toisintaminen ja palvelemaan lyhytnäköisiä kilpailukyvyn, tuottavuuden ja talouskasvun tavoitteita (Sterling 2003; Värri 2018; Nussbaum 2011). Samaan aikaan odotuksena kuitenkin on, että koulutus ja oppiminen uudistaisivat yhteiskuntaa kestävämmäksi (Sterling 2003; Perusopetuksen opetussuunnitelman perustusteet 2014; Lukion opetussuunnitelman perusteet 2015; Varhaiskasvatussuunnitelman perusteet 2018). Koulujärjestelmä on systeemisesti alisteinen yhteiskunnalle. Koska koulutuksen pitäisi kyetä muuttamaan samaa yhteiskuntaa, jolle sen toiminta on alisteinen, voi muutos tapahtua ainoastaan vuorovaikutuksessa yhteiskunnan kanssa. (Sterling 2003.)

Luomme tässä katsauksessa analyyttisen tarkastelukehyksen, jonka avulla koulutusorganisaatiot voivat tunnistaa oman yhteiskunnallisen tehtävänsä ja halutessaan omaksua tarkoituksekseen yhteiskunnan uudistamisen ja kestävän tulevaisuuden rakentamisen. Etsimme ratkaisua koulutusjärjestelmän rakenteelliseen dilemmaan, jossa koulutuksen tehtävänä on samanaikaisesti olemassa olevan yhteiskunnan toisintaminen sekä sosiaalisen ja kulttuurisen muutoksen aikaansaaminen. Ehdotamme koulutusorganisaation toiminnan uudelleen suuntaamisen tueksi viitekehystä, jonka avulla voidaan tunnistaa, miten organisaatio heijastaa toiminnassaan olemassa olevaa toisintavaa, tulevaisuutta ennakoivaa ja yhteiskuntaa uudistavaa orientaatiota. Tavoittelemme sellaista organisaation paradigman uudistumista, jossa transformatiivisuus laajenee yksilön oppimisesta yhteisölliseksi sosiaalipedagogiikaksi ja kumuloituu uudistavien kehittämiskumppanuuksien kautta yhteiskunnalliseksi muutokseksi. Tämä ajattelu on normiohjatussa koulutusjärjestelmässä uutta ja idealistista, mutta sille on tarvetta, sillä aivan ilmeisesti yhteiskunta ei pysty vastaamaan eskaloituviin kestävyysongelmiin pelkästään vanhoilla keinoilla.

\section{Edistysajattelun uudistamisen lähtökohtia}

Transformatiivinen oppiminen viittaa oppimiseen, joka uudistaa perustavanlaatuisia käsityksiä ihmisenä olemisesta ja ihmisen suhteesta ympäröivään todellisuuteen (O’Sullivan, Morrell \& O'Connor 2002). Ihmisen ja yhteisöjen oppimista voi tapahtua kolmella tasolla, joita ovat kognitiivinen, metakognitivinen ja episteeminen oppiminen (Bateson 1972; Sterling 2003; 2010). Tasojen ideaa kuvaa metafora metsästä. Ensimmäisen eli kognitiivisen tason oppimisessa keskitytään tekemään olemassa olevia asioita paremmin. Sitä voi verrata metsän sisällä olemiseen. Toisel- 
la eli metakognitiivisen oppimisen tasolla siirrytään reflektiiviseen oppimiseen. Silloin tullaan ulos metsästä, pystytään näkemään metsä kokonaisuutena ja luodaan käsityksiä toisenlaisesta metsästä tai paradigmasta. Kolmannella eli episteemisen oppimisen tasolla irrotaan ajattelun rajoituksista ja noustaan katsomaan todellisuutta helikopterinäkymästä. Nähdään, että on mahdollista tehdä valintoja useiden erilaisten metsien (paradigmojen) välillä. Tämä episteeminen taso johtaa transformatiiviseen oppimiseen ja uuden paradigman sisäistämiseen. (Sterling 2003.)

Ilmastonmuutoksen torjuminen toimii esimerkkinä askelluksesta oppimisen eri tasoilla (Laininen 2018a). Ilmastonmuutosta on pitkään pyritty ratkaisemaan kognitiivisen oppimisen keinoin parantamalla tuotannon energia- ja materiaalitehokkuutta, kierrättämällä ja tekemällä päästökauppaa. Viime aikoina on siirrytty metakognitiivisen oppimisen tasolle valjastamalla käyttöön uusiutuva energia, kiertotalous, digitalisaatio ja vastuullinen kuluttaminen. Ne edustavat systeemistä uudistusta, jonka avulla ilmastonmuutoksen ongelma pyritään ratkaisemaan. Haasteeksi muodostuu se, että kasvun pakkoon perustuvassa taloudessa nämä ratkaisut uhkaavat jäädä oireiden hoitamiseksi ainoastaan hidastaen kestävyysongelmien kriisiytymistä. Itse sairauden ytimeen ne eivät ulotu, sillä ratkaisuja etsitään edelleen nykyisen maailmankäsityksemme sisältä ilman sen kriittistä reflektointia (Sterling 2010; 2019).

Kestävien ratkaisujen löytäminen näyttää edellyttävän episteemistä oppimista, joka mahdollistaa nykyisen edistyksen ihanteen perustekijöiden kyseenalaistamisen ja todellisuuden tulkintojen uudistamisen. Länsimaisen modernismin maailmankuvaa voidaan kritisoida harhaisesta todellisuuskäsityksestä, jonka ilmentymiä ovat muun muassa käsitys ihmisen ja muun luonnon erillisyydestä, käsitys talouden itseisarvoisuudesta ja sen irrallisuudesta biosfääristä sekä käsitys rajattoman talouskasvun mahdollisuudesta rajallisella maapallolla (Bateson 1972; Sterling 2019; Lehtonen, Salonen, Cantell \& Riuttanen 2018). Ihmisenä olemisen ydinkysymykset ovat avainasemassa maailmankuvan uudistamisessa: Mikä loppujen lopuksi tekee ihmisen elämästä elämisen arvoista? Tapahtuuko elintason jatkuva parantaminen elämänlaadun kustannuksella? Kuinka suuri talous olisi sopivasti suuri?

Varhaiskasvatussuunnitelman perusteiden sekä perusopetuksen ja lukion opetussuunnitelmien perusteiden arvoperustassa oleva ekososiaalinen sivistyskäsitys on yksi mahdollisuus uudistaa oppimista (Perusopetuksen opetussuunnitelman perustusteet 2014; Lukion opetussuunnitel- 
man perusteet 2015; Varhaiskasvatussuunnitelman perusteet 2018; Laininen 2018b). Ekososiaalisuuden lähtöajatuksena on se, että sekä ekologisella että sosiaalisella ympäristöllä on suora vaikutus ihmisen hyvinvointiin (Mathlin 2018; Närhi 2004). Ekososiaalisesti sivistynyt ihminen tunnistaa ihmisen, muun luonnon ja yhteiskunnan keskinäisriippuvuudet paikallisella ja globaalilla tasolla. Ekososiaalinen sivistys perustuu arvohierarkialle, joka tunnustaa ihmisen ja koko sivilisaatiomme täydellisen riippuvaisuuden luonnosta. Ihmiskunnan elinehto on toimiminen luonnon kantokyvyn rajoissa. Edistyksen päämääränä on arvokkaan ja merkityksellisen elämän mahdollistaminen kaikille maailman ihmisille. Talous on väline riittävän aineellisen hyvinvoinnin turvaamiseen sen sijaan, että tavoitellaan itseisarvoisesti talouden kasvattamista. (Salonen \& Bardy 2015.)

Ekososiaalisen sivistyskäsityksen arvopohja rakentuu vastuullisuudelle, kohtuullisuudelle ja ihmistenvälisyydelle. Vastuullisuuteen kasvamisen ytimessä on ihmisen eettisen huolenpidon piirin laajentuminen omasta lähipiiristä maailmankansalaisuuteen, elolliseen ja elottomaan luontoon sekä tuleviin sukupolviin. Kohtuullisuuden sisäistäminen perustuu halujen ja tarpeiden erottamiseen toisistaan. Tyytyväisyys on onnistumista omassa subjektiivisesti määrittyvässä riittävyyden tarkastelussa. Ihmistenvälisyys tarjoaa ratkaisun kohtuuden löytämisen ongelmaan. Ihmistenvälisyyden elämää kannatteleva voima perustuu tunnustukseen ja arvostukseen, jotka ovat omiaan tuomaan pysyvää tyytyväisyyttä ihmisenä olemiseen. Se toimii vastavoimana jatkuvaa riittämättömyyden ja mitättömyyden tunnetta synnyttävälle kuluttamisen kehälle. (Laininen 2018b; Salonen \& Bardy 2015; Värri 2018; Pulkki 2017.)

\section{Koulutusorganisaation orientaatiot ja paradigmamuutos}

Edellä esiteltyä oppimisen tasojen teoriaa voidaan soveltaa koulutusorganisaatioiden oppimiseen ja paradigman muutokseen kohti ekososiaalista sivistystä (Sterling 2003). Luomme viitekehyksen, jonka avulla voidaan tarkastella, miten koulutusorganisaatio heijastaa toiminnassaan olemassa olevaa toisintavaa orientaatiota (kognitiivinen taso), tulevaisuutta ennakoivaa orientaatiota (metakognitiivinen taso) ja yhteiskuntaa uudistavaa orientaatiota (transformatiivinen taso). Rinnastamme mallissamme yhteiskuntaa uudistavan orientaation episteemisen tason oppimisesta seuraavaan transformatiiviseen oppimiseen, joka kuvastaa oppimisen aikaansaamaa muutosta organisaatiossa ja yhteiskunnassa.

Olemassa olevaa toisintavalla tasolla koulutusorganisaation uudistu- 
minen rajoittuu tehokkuuden parantamiseen. Tulevaisuutta ennakoivalla tasolla organisaatio pystyy kriittiseen ja reflektoivaan oppimiseen ja aktiiviseen vuorovaikutukseen toimintaympäristönsä kanssa. Yhteiskuntaa uudistavalla tasolla koulutusorganisaatio kykenee transformatiiviseen oppimiseen, joka muuttaa koulutuksen paradigmaa. Organisaatio ottaa tulevaisuuden haltuunsa ja ryhtyy uudistamaan yhteiskuntaa kumppaneidensa kanssa. (Sterling 2003; 2010.)

Kysymys on organisatorisesta emansipoitumisesta, sillä paradigmamuutoksen toteutuminen edellyttää koulutusorganisaation osittaista vapautumista yhteiskunnan koulutukseen kohdistamista sosialisaatio-odotuksista. Jotta organisaatio kykenee uudistamaan yhteiskunnallista tehtäväänsä, sen täytyy tulla tietoiseksi vallitsevasta yhteiskunnallisesta orientaatiostaan. Ehdotamme koulutusorganisaation toiminnan analysoimisen avuksi seuraavia muutoksentekijöitä, joiden avulla koulutusorganisaation tulevaisuus- ja muutosorientaatiota on mahdollista reflektoida ja samalla hahmottaa paradigman muutospolkua: a) organisaation suhde yhteiskuntaan, b) emergenssi eli organisaatiosta nouseva uudistuminen, c) tulevaisuusorientaatio ja d) oppimiskäsitys (ks. Kuvio 1).

\begin{tabular}{|c|c|c|c|}
\hline & \multicolumn{3}{|c|}{$\begin{array}{l}\text { KOULUTUSORGANISAATION PARADIGMAMUUTOS } \\
---------------\rightarrow\end{array}$} \\
\hline & $\begin{array}{l}\text { OLEMASSA OLEVAA } \\
\text { TOISINTAVAA }\end{array}$ & $\begin{array}{l}\text { TULEVAISUUTTA } \\
\text { ENNAKOIVA }\end{array}$ & $\begin{array}{l}\text { YHTEISKUNTAA } \\
\text { UUDISTAVA }\end{array}$ \\
\hline $\begin{array}{l}\text { SUHDE YHTEIS- } \\
\text { KUNTAAN }\end{array}$ & $\begin{array}{l}\text { - Erillinen } \\
\text { - Hyödyntävä } \\
\text { - Organisaatiokeskeisyys }\end{array}$ & $\begin{array}{l}\text { - Vuorovaikutteinen } \\
\text { - Kumppanuus } \\
\text { - Alueellisuus }\end{array}$ & $\begin{array}{l}\text { - Sulautunut } \\
\text { - Yhteiskehittäminen } \\
\text { - Globaalisuus }\end{array}$ \\
\hline EMERGENSSI & $\begin{array}{l}\text { - Siiloutuminen } \\
\text { - Yhdenmukaisuus } \\
\text { - Tiedottaminen } \\
\text { - Normit ja vastuut }\end{array}$ & $\begin{array}{l}\text { - Yhteydet } \\
\text { - Organisaation moninaisuus } \\
\text { - Sisäinen dialogisuus } \\
\text { - Vapaudet ja vastuut }\end{array}$ & $\begin{array}{l}\text { - Verkostot } \\
\text { - Verkoston moninaisuus } \\
\text { - Kulttuurinen dialogi } \\
\text { - Itseorganisoituminen }\end{array}$ \\
\hline $\begin{array}{l}\text { TULEVAISUUS- } \\
\text { ORIENTAATIO }\end{array}$ & $\begin{array}{l}\text { - Lineaarinen ennakointi } \\
\text { - Reaktiivisuus ja } \\
\text { säilyttäminen }\end{array}$ & $\begin{array}{l}\text { - Skenaarioajattelu } \\
\text { - Proaktiivisuus ja } \\
\text { uudistuminen }\end{array}$ & $\begin{array}{l}\text { - Utoopinen ajattelu } \\
\text { - Antisipaatio ja } \\
\text { uudistaminen }\end{array}$ \\
\hline $\begin{array}{l}\text { OPPIMIS- } \\
\text { KÄSITYS }\end{array}$ & $\begin{array}{l}\text { - Oppiminen toisintajana } \\
\text { - Yksilö oppijana }\end{array}$ & $\begin{array}{l}\text { - Oppiminen muutosta varten } \\
\text { - Yhteisö oppijana }\end{array}$ & $\begin{array}{l}\text { - Oppiminen muutoksena } \\
\text { - Verkosto oppijana }\end{array}$ \\
\hline
\end{tabular}

KUVIO 1. Koulutusorganisaation paradigman muutoksentekijät ja niiden ilmeneminen olemassa olevaa toisintavan (kognitiivinen), tulevaisuutta ennakoivan (metakognitiivinen) ja yhteiskuntaa uudistavan (transformatiivinen) orientaation tasoilla. 
Muutoksentekijät ilmentävät samanaikaisesti sekä paradigman tasojen toteutumista että mahdollistavat paradigman uudistumisen: tulevaisuutta ennakoivan tason piirteiden vahvistuminen muutoksen tekijöissä avaa mahdollisuuden uudistavan orientaation esiin nousemiselle. Organisaation toiminnassa on aina olemassa samanaikaisesti piirteitä eri orientaatioista. Ideaalia ei ole myöskään tavoitella pelkästään uudistavaa orientaatiota, sillä organisaatio tarvitsee myös olemassa olevaa toisintavia rakenteita pysyäkseen koossa ja ylipäätään kyetäkseen uudistumaan.

Koulutusorganisaation suhde yhteiskuntaan on keskeinen muutoksentekijä, sillä oppilaitokset ovat yhteiskunnan alajärjestelmiä, jolloin niiden radikaali uudistuminen on mahdollista vain yhteisevoluutiossa yhteiskunnan kanssa (Sterling 2003). Olemassa olevaa toisintavalla tasolla oppilaitos näkee itsensä yhteiskunnasta erillisenä toimijana, joka tuottaa normien mukaista osaamista yhteiskunnalle. Toimintaa ohjaa organisaatiokeskeinen ajattelu ja suhde muihin toimijoihin on kilpaileva ja hyödyntävä. Tulevaisuutta ennakoivalla tasolla suhde muuttuu vuorovaikutteiseksi ja näkökulma laajenee alueelliseksi. Pyrkimyksenä on asiakaslähtöinen koulutus ja molempia osapuolia hyödyttävien kumppanuuksien rakentaminen. Yhteiskuntaa uudistavalla tasolla organisaatio mieltää itsensä sulautuneena yhteiskunnan osana. Suhde muihin toimijoihin perustuu uutta luovaan rikastavaan dialogiin ja kestävien ratkaisujen yhteiskehittämiseen. Näkökulma laajenee globaaliksi.

Toinen muutoksentekijä on koulutusorganisaation paradigman uudistumisen emergentti luonne. Edellä kuvattu koulutuksen kestävyystavoitteiden alisteisuus koulutuksen muille tavoitteille ja yhteiskunnan odotuksille johtaa siihen, että uudistuminen ei tapahdu ylhäältä ohjattuna, vaan se perustuu organisaatiosta nousevaan muutokseen eli emergenssiin (Sterling 2003). Systeemiteoreettisesti tarkasteltuna emergenssiä vahvistavat organisaatiossa vallitsevat yhteydet, kulttuurien, ajattelun ja tunneilmaston moninaisuus sekä informaatiovirta. Emergenssiä voidaan tukea myös muun muassa rakentamalla yhteisiä visioita, jakamalla vastuuta ja johtajuutta, tukemalla myönteistä ilmapiiriä ja vahvistamalla yhteisön osallisuutta organisaation uuden yhteisen identiteetin rakentamisessa. (Seel 2006; Senge 1990.)

Olemassa olevaa toisintavalla tasolla organisaation siiloutuminen ja hierarkkisuus estävät yhteyksien rakentumista. Informaation kulku on yksisuuntaista ja mahdollisuudet sisäiselle vuoropuhelulle rajattuja. Vahva yhtenäiskulttuuri ja johtaminen tukahduttavat moninaisuuden. Tu- 
levaisuutta ennakoivalla tasolla emergenssiä ehkäiseviä rakenteita puretaan tietoisesti esimerkiksi vahvistamalla tiimien, yksiköiden ja opiskelijoiden vuorovaikutusta, mahdollistamalla rikastava moniääninen dialogi sekä jakamalla vastuuta ja antamalla vapauksia. (Seel 2016; Salonen 2019.) Emergenssin voidaan ajatella laajentuvan myös koulutusorganisaation ja sidosryhmien yhteiseksi uudistumiseksi (yhteiskuntaa uudistava taso). Keskiöön nousee tällöin verkostossa tapahtuva uutta luova kulttuurinen dialogi ja mahdollisuus uusien rakenteiden syntymiseen itseorganisoitumisen kautta.

Kolmas muutoksentekijä on koulutusorganisaation tulevaisuusorientaatio. Sen laatua voidaan arvioida tarkastelemalla toiminnan ja päätöksenteon perustana olevaa ajattelua: nähdäänkö tulevaisuuden rakentuvan lineaarisesti nykyisen kehityksen jatkumona (olemassa olevaa toisintava taso), hyödynnetäänkö skenaarioita todennäköisistä tulevaisuuksista (tulevaisuutta ennakoiva taso) vai laajennetaanko tarkastelua mahdollisiin vaihtoehtoisiin tulevaisuuksiin utooppista ajattelua soveltaen (yhteiskuntaa uudistava taso). Uudistavaan tasoon linkittyy myös antisipaatio eli tulevaisuuslukutaito, jossa tulevaisuuskuvia pyritään aktiivisesti käyttämään nykyhetkessä ja sitä kautta vaikuttamaan toivotun tulevaisuuden syntymiseen. (Poli 2017; Pouru \& Wilenius 2018.)

Neljäs muutoksentekijä on oppimiskäsitys. Olemassa olevaa toisintavalla tasolla oppiminen ilmenee yksilötason prosessina. Oppija omaksuu substanssitietoa, jonka avulla hän pystyy toimimaan yhteiskunnan jäsenenä vahvistaen nykyistä yhteiskunnallista kehitystä (kognitiivinen oppiminen). Tulevaisuutta ennakoivalla tasolla opitaan muutosta varten (metakognitiivinen oppiminen). Koulutusorganisaatiossa vahvistuvat oppivan organisaation piirteet: mm. yhteisön oppiminen, käsitysten ja toimintatapojen kriittinen arviointi, systeeminen ajattelu ja jaettujen visioiden synnyttäminen. Pyrkimyksenä on yhteisten arvojen ja merkityksen rakentaminen ja organisaation uudistuminen. Yhteiskuntaa uudistavalla tasolla oppiminen laajenee verkostoihin ja oppimisesta tulee muutoksen tekemistä (transformatiivinen oppiminen). (Sterling 2003; Senge 1990; Laininen 2018a.)

\section{Lopuksi}

Vallitseva ajattelu kestävää tulevaisuutta edistävästä oppimisesta on integroivaa. Toisin sanoen kestävä kehitys pyritään kytkemään osaksi eri oppiaineiden opetusta. Ratkaisu jättää kestävyyteen liittyvien kysymysten 
tarkastelun alisteiseksi koulutuksen muille tavoitteille ja yhteiskunnan odotuksille. Tämän vuoksi koulutuksen uudistamista on perusteltua lähestyä kokonaisvaltaisesti kysymällä mitä tarkoitusta varten koulu on olemassa yhteiskunnassa. (Sterling 2003.)

Ekososiaalinen sivistyskäsitys tarjoaa varteenotettavan lähtökohdan koulutuksen uudistumisprosessille. Paradigman muutoksen edetessä kestävyyskysymykset aletaan nähdä systeemisinä ilmiöinä, joita tarkastellaan oppiaine- ja tiederajat ylittäen. Vallitsevan koulutuksen paradigman uudistamistarve tunnistetaan ja aletaan etsiä vaihtoehtoista paradigmaa. Muutos syvenee yhteisön toimintaa ohjaavien ontologisten käsitysten uudistumiseen: organisaation suhde yhteiskuntaan ja biosfääriin, luontokäsitys, ihmiskäsitys sekä käsitys ihmisen suhteesta talouteen ja teknologiaan. Yhteiskuntaa uudistavan koulutusorganisaation idean toteutuminen merkitsee siten koulutuksen paradigman ja organisaation tarkoituksen uudistumista ekososiaalisen sivistyksen ajattelun perustalle. Yhteiskunta, koulutus ja oppijat hahmotetaan osana globaalia yhteisöä ja biosfääriä, ja oppiminen ja tulevaisuuden rakentaminen tapahtuvat tämän ymmärryksen pohjalta. (Sterling 2003; Salonen \& Bardy 2015; Folke ym. 2016; Salonen \& Siirilä 2019.)

Paradigman muutosta tukee koulutusorganisaation yhteiskunnallisen orientaation tunnistaminen. Esittämäämme viitekehystä on mahdollista soveltaa oppilaitoksen toimintoihin. Tältä pohjalta voidaan rakentaa indikaattoreita, joiden avulla oppilaitos voi arvioida ja kehittää toimintaansa. Oppilaitos ei pysty hetkessä muuttumaan yhteiskuntaa uudistavaksi toimijaksi. Siksi oppilaitoksen on kyettävä hahmottamaan sisäisen emergentin muutosprosessinsa luonnetta ja sen rinnalla tapahtuvaa yhteiskunnallista muutosta. Utooppinen ajattelu ja tulevaisuusmuistelu tarjoavat mahdollisuuden kuvailla, miten muutosprosessi tulevaisuutta ennakoivaksi ja yhteiskuntaa uudistavaksi toimijaksi tapahtuu vuorovaikutuksessa ympäröivän yhteiskunnan kanssa. (OKKA-säätiö 2019; Lakkala 2017; Phdungsilp 2011.)

Yhteiskuntaa uudistava koulutusorganisaatio kykenee kyseenalaistamaan olemassa olevat yhteiskunnalliset tarpeet ja synnyttää kansalaisten jokapäiväistä elämää kannattelevia merkityksiä. Tämä ei voi onnistua ilman koulutusorganisaation, sen opiskelijoiden ja sidosryhmien valtuuttamista ja voimaannuttamista muutoksen tekijöiksi. Uudistumisen vastapainoksi niin kansalainen, koulutusorganisaatio kuin yhteiskuntakin tarvitsevat myös olemassa olevaa toisintavia rakenteita. Siksi ei ole edes 
ideaalia tavoitella pelkästään yhteiskuntaa uudistavaa orientaatiota. Eri orientaatioiden mukaisesti toimiva koulutusorganisaatio tuottaa erilaista kehitystä edistävää osaamista yhteiskuntaan. Olemassa olevaa toisintava orientaatio palvelee tehokkuuden ja tuottavuuden parantamista. Tulevaisuutta ennakoiva orientaatio vahvistaa uusien tuotanto- ja palveluratkaisujen kehittämistä. Yhteiskuntaa uudistava taso synnyttää osaamista, joka tähtää tarpeiden uudelleen määrittelyyn ja systeemitason muutokseen.

\section{LÄHTEET}

Bateson, G. 1972. Steps to an Ecology of Mind. San Francisco: Chandler.

BIOS-tutkimusyksikkö 2018. Maailman aineksen käyttö kasvaa kasvamistaan - minne ja kenelle luonnonvarat virtaavat? Saatavissa http://bios.fi/maailman-aineksen-kayttokasvaa-kasvamistaan-minne-ja-kenelle-luonnonvarat-virtaavat/ (haettu 22.4.2019).

Folke, C., Biggs, R., Norström, A. V., Reyers, B. \& Rockström, J. 2016. Social-ecological resilience and biosphere-based sustainability science. Ecology and Society 21 (3), 41. Saatavissa https://dx.doi.org/10.5751/ES-08748-210341 (haettu 22.4.2019).

Järvensivu, P. 2019. Entä jos ilmastopäästöt nollataan oikeasti? Teoksessa J. Aunesluoma \& S. Kansikas (toim.) Euroopan villit kortit ja mustat joutsenet. Eduskunnan tulevaisuusvaliokunnan julkaisu 6/2018, 72-76. Saatavissa https://www.eduskunta.fi/ FI/lakiensaataminen/valiokunnat/tulevaisuusvaliokunta/julkaisut/Sivut/euroopanvillit-kortit-ja-mustat-joutsenet.aspx (haettu 22.4.2019).

Laininen, E. 2018a. Transforming Our Worldview Towards a Sustainable Future. Teoksessa J. Cook (toim.) Sustainability, Human Well-Being and the Future of Education. Basingstoke: Palgrave Macmillan, 161-200. Saatavissa https://dx.doi. org/10.1007/978-3-319-78580-6 (haettu 22.4.2019).

Laininen, E. 2018b. Transformatiivinen oppiminen ekososiaalisen sivistymisen mahdollistajana. Ammattikasvatuksen aikakauskirja 20 (5), 16-38. Saatavissa https:// akakk.fi/ammattikasvatuksen-aikakauskirja-05-2018-digitaalinen-erikoisnumero/ (haettu 22.4.2019).

Lakkala, K. 2017. Utopia yhteiskunnallisen mielikuvituksen metodologiana. Futura 36 (1), 14-21.

Lehtonen, A., Salonen, A., Cantell, H. \& Riuttanen, L. 2018. A pedagogy of interconnectedness for encountering climate change as a wicked sustainability problem. Journal of Cleaner Production 199 (20), 860-867.

Lukion opetussuunnitelman perusteet 2015. Saatavissa https://www.oph.fi/sites/default/ files/documents/172124_lukion_opetussuunnitelman_perusteet_2015.pdf (haettu 26.11.2019). 
Mathlin, V. M. 2018. Mitä on ekososiaalinen sivistys ja mikä yhteys sillä on sivistyksen käsitteeseen? Kasvatustieteen kandidaatintutkielma. Oulu: Oulun yliopisto. Saatavissa http://jultika.oulu.fi/files/nbnfioulu-201811223089.pdf (haettu 22.4.2019).

Nussbaum, M. 2011. Talouskasvua tärkeämpää. Suom. Timo Soukola. Helsinki: Gaudeamus.

Närhi, K. 2004. The Eco-social Approach in Social Work and the Challenges to the Expertise of Social Work. Jyväskylä: University of Jyväskylä. Saatavissa https://jyx. jyu.fi/bitstream/handle/123456789/13326/9513918343.pdf? sequence $=1$ (haettu 22.4.2019).

OKKA-säätiö 2019. Kestävän tulevaisuuden indikaattoreiden taustamateriaali. Saatavissa http://koulujaymparisto.fi/tukea-kestavan-kehityksen-tyohon/kestavantulevaisuuden-indikaattoreiden-taustamateriaali/ (haettu 22.4.2019).

O’Sullivan, E., Morrell, M. \& O’Connor, M. A. 2002. Expanding the Boundaries of Transformative Learning. Essays on Theory and Practice. New York: Palgrave. Saatavissa https://dx.doi.org/ 10.1007/978-1-349-63550-4 (haettu 8.11.2019).

Perusopetuksen opetussuunnitelman perusteet 2014. https://www.oph.fi/sites/default/ files/documents/perusopetuksen_opetussuunnitelman_perusteet_2014.pdf (haettu 26.11.2019).

Phdungsilp, A. 2011. Futures Studies' Backcasting Method Used for Strategic Sustainable City Planning. Futures 43, 707-714.

Poli, R. 2017. Introduction to Anticipation Studies. Cham: Springer. Saatavissa https:// dx.doi.org/10.1007/978-3-319-63023-6 (haettu 7.11.2019).

Pouru, L. \& Wilenius, M. 2018. Tulevaisuuslukutaito navigaatiovälineenä kuudennessa aallossa: kuinka integroida tulevaisuus lukio-opetukseen? Futura 37 (3), 12-23.

Pulkki, J. 2017. Kilpailun kasvatuksellisista ongelmista. Hyveitä 2000-luvulle. Väitöskirja. Tampere: Tampereen yliopisto, kasvatustieteellinen tiedekunta. Acta Universitatis Tamperensis 2332. Tampere University Press. Saatavissa http://urn.fi/ URN:ISBN:978-952-03-0592-5 (haettu 22.4.2019).

Salonen, A. 2019. Transformative responses to sustainability. Teoksessa L. Filho W. (toim.) Encyclopedia of Sustainability in Higher Education. Cham: Springer. Saatavissa https://doi.org/10.1007/978-3-319-63951-2_501-1 (haettu 7.11.2019).

Salonen, A. \& Bardy, M. 2015. Ekososiaalinen sivistys herättää luottamusta tulevaisuuteen. Aikuiskasvatus 35 (1), 4-15.

Salonen, A. \& Siirilä, J. 2019. Transformative Pedagogies for Sustainable Development. Teoksessa L. Filho W. (toim.) Encyclopedia of Sustainability in Higher Education. Cham: Springer. Saatavissa https://doi.org/10.1007/978-3-319-63951-2_369-1 (haettu 7.11.2019).

Seel, R. 2006. Emergence in Organisations. London: New Paradigm Consulting. Saatavissa http://www.new-paradigm.co.uk/emergence-2.htm (haettu 22.4.2019).

Senge, P. 1990. The Fifth Discipline. New York: Currency Doubleday. 
Steffen, W., Richardson, K., Rockström, J., Cornell, S. E., Fetzer, I., Bennett, E. M., Biggs, R., Carpenter, S. R., de Vries, W., de Wit, C. A., Folke, C., Gerten, D., Heinke, J., Mace, G. M., Persson, L. M., Ramanathan, V., Reyers, B. \& Sorlin, S. 2015. Planetary boundaries: Guiding human development on a changing planet. Science 347 (6223), 736-746. Saatavissa https://dx.doi.org/10.1126/science.1259855 (haettu 7.11.2019).

Sterling, S. 2003. Whole Systems Thinking as a Basis for Paradigm Change in Education: explorations in the context of sustainability. $\mathrm{PhD}$ thesis. Bath: Centre for Research in Education and the Environment, University of Bath. Saatavissa http://www.bath. ac.uk/cree/sterling/sterlingthesis.pdf (haettu 22.4.2019).

Sterling, S. 2010. Transformative Learning and Sustainability: sketching the conceptual ground, Learning and Teaching in Higher Education 11 (5), 17-33.

Sterling, S. 2019. Planetary Primacy and the Necessity of Positive Dis-Illusion. Sustainability: The Journal of Record 12 (2), 60-63. Saatavissa https://doi.org/10.1089/ sus.2019.29157 (haettu 22.4.2019).

Vaden, T., Lähde, V., Majava, A., Toivanen, T., Eronen, J. T. \& Järvensivu, P. 2019. Onnistunut irtikytkentä Suomessa? Alue Ja Ympäristö 48 (1), 3-13. Saatavissa https://doi.org/10.30663/ay.76338 (haettu 7.11.2019).

Varhaiskasvatussuunnitelman perusteet 2018. Saatavissa https://www.oph.fi/sites/ default/files/documents/varhaiskasvatussuunnitelman_perusteet.pdf (haettu 26.11.2019).

Värri, V-M. 2018. Kasvatus ekokriisin aikakaudella. Vastapaino: Tampere. 